\title{
Spondylodiscitis due to transmitted mycotic aortic aneurysm or infected grafts after endovascular aortic aneurysm repair (EVAR): A retrospective single-centre experience with short-term outcomes
}

\author{
Nicolas Heinz von der Höh ${ }^{1}$ (1) - Philipp Pieroh ${ }^{1}$ · Jeanette Henkelmann ${ }^{2}$ • Daniela Branzan ${ }^{3}$ · Anna Völker ${ }^{1}$. \\ Dina Wiersbicki ${ }^{1}$. Christoph-Eckhard Heyde ${ }^{1}$
}

Received: 30 April 2020 / Accepted: 25 August 2020 / Published online: 7 September 2020

(c) The Author(s) 2020

\begin{abstract}
Purpose To report the challenging therapeutic approach and the clinical outcome of patients with pyogenic spondylodiscitis transmitted due to infected retroperitoneal regions of primary infected mycotic aortic aneurysms (MAAs) or secondary infected aortic stent grafts after endovascular aneurysm repair (EVAR).

Methods Between 2012 and 2019, all patients suffering from spondylodiscitis based on a transmitted infection after the EVAR procedure were retrospectively identified. Patient data were analysed regarding the time between primary and secondary EVAR infection and spondylodiscitis detection, potential source of infection, pathogens, antibiotic treatment, complications, recovery from infection, mortality, numeric rating scale (NRS), COBB angle and cage subsidence.

Results Fifteen patients with spondylodiscitis transmitted from primary or secondary infected aortic aneurysms after EVAR were included. The median follow-up time was 8 months (range 1-47). Surgery for spondylodiscitis was performed in 12 patients. In 9 patients, the infected graft was treated conservatively. MAAs were treated in 4 patients first with percutaneous aortic stent graft implantation followed by posterior surgery of the infected spinal region in a two-step procedure. Infection recovery was recorded in 11 patients during follow-up. The overall mortality rate was $27 \%(n=4)$. The mean pain intensity improved from an NRS score of 8.4 (3.2-8.3) to 3.1 (1.3-6.7) at the last follow-up.

Conclusion EVAR was used predominantly to treat primary infected MAAs. Secondary infected grafts were treated conservatively. Independent of vascular therapy, surgery of the spine led to recovery in most cases. Thus, surgery should be considered for the treatment of EVAR- and MAA-related spondylodiscitis.
\end{abstract}

Keywords Spondylodiscitis $\cdot$ Vertebral osteomyelitis $\cdot$ AAA $\cdot$ EVAR $\cdot$ Surgery

\section{Introduction}

Nicolas Heinz von der Höh and Pieroh Philipp have contributed equally to this work.

Nicolas Heinz von der Höh

Nicolas.vonderHoeh@medizin.uni-leipzig.de

1 Department of Orthopaedic, Trauma and Plastic Surgery, University Hospital Leipzig, Liebigstr. 18, 04103 Leipzig, Germany

2 Department for Diagnostic and Interventional Radiology, University Hospital Leipzig, Liebigstr. 18, 04103 Leipzig, Germany

3 Department of Visceral, Transplant, Thorax and Vascular Surgery, University Hospital Leipzig, Liebigstr. 18, 04103 Leipzig, Germany
In recent years, the increase in percutaneous endovascular aortic repair (EVAR) for the treatment of aortic diseases has been associated with reports of post-reconstruction complications $[1,2]$. The most serious post-EVAR complication is infection of the stent graft [1]. As a result, skin contamination is reported in 10-20\% of cases with haematogenic spread [3]. The perioperative and total mortality rates range from 12 to $20 \%$ after surgical revision of infected stent grafts $[3,4]$. Notably, it is valuable to differentiate between (mycotic) aortic aneurysms (primary infection) and stent graft infections following EVAR (secondary infection).

Mycotic aortic aneurysms (MAAs) were defined by Sir William Osler in 1885 . To decrease the mortality from open 
surgery in elderly and frail patients, MAAs can be treated with EVAR [4].

In very rare cases, the infection may proceed from primary or secondary infections of the aneurysm to the native aorta and the paraaortic environment affecting the retroperitoneal space, resulting in spondylodiscitis with pain, instability and/or neurological complications. Considering the treatment of spondylodiscitis only, the therapy consists of the prevention of infection spread and recovery from infection. In the majority of cases, conservative therapy is the sole treatment. In the case of neurologic deficits and/ or destruction or instability, surgery should be considered. Nonetheless, overall mortality rates up to $20 \%$ have been reported in the treatment of spondylodiscitis [5].

Currently, a few case reports and a radiological case series exist reporting on EVAR infection-related spondylodiscitis (Table 1) [6-13].Thus far, treatment algorithms for this interdisciplinary challenge are missing. Therefore, we present a single-centre experience of 15 patients focusing on the treatment, complications and short-term follow-up.

\section{Materials and methods}

The study is in accordance with the Declaration of Helsinki and with local legislation. The study was reviewed and approved by our local ethics committee.

In one level 1 trauma centre with subspecialties in spine, vascular and endovascular surgery, all patients suffering from a primary infected MAA after treatment with EVAR or secondary infected EVAR-related spondylodiscitis were identified from January 2012 to June 2019. The diagnosis of EVAR graft-related infection was defined by a combination of inflammatory markers, 18F-fluorodeoxyglucose positron emission tomography (PET)/CT or MRI imaging, specimen cultures and/or histological examination.

We excluded all patients with spondylodiscitis without infection from EVAR and patients with infections from EVAR, but without spondylodiscitis.

Surgical care was provided by anterior, posterior or combined approaches. The posterior approach was used to perform debridement of the intervertebral disc after spinal decompression via laminotomy or laminectomy. After exposure of the intervertebral disc space, the disc space was cleaned with a rongeur, curettes and shavers while protecting the neural structures. Therefore, material for the histological and microbiological examinations was obtained. The intervertebral disc space was then irrigated with physiological buffered saline until no macroscopically visible contamination was observed. With the posterior approach, epidural abscesses and even psoas abscesses could be accessed through the intervertebral disc and with the insertion of a flexible catheter. If a psoas abscess was present, it was relieved by posteriorly opening the annulus of the intervertebral disc and cleaning it with a rinsing catheter.

After that, the cage height was measured, and an oblique titanium-coated polyetheretherketone (PEEK) cage was implanted. The cage had a perforation that was prepared

Table 1 Summary of the previous case series on Spondylodiscitis due to transmitted mycotic aortic aneurysm or infected grafts after endovascular aortic aneurysm repair (EVAR)

\begin{tabular}{|c|c|c|c|c|c|c|}
\hline Author/year & Patients $(n)$ & $\begin{array}{l}\text { Vascular infection } \\
\text { (primary or second- } \\
\text { ary) }\end{array}$ & $\begin{array}{l}\text { Infected spinal } \\
\text { region }\end{array}$ & Vascular treatment & Spine treatment & $\begin{array}{l}\text { Duration of antibiotic } \\
\text { treatment }\end{array}$ \\
\hline Blanch (2010) & 2 & Secondary & Lumbar & $\begin{array}{l}1 \times \text { removal and } \\
\text { bypass; } 1 \times \text { con- } \\
\text { servative }\end{array}$ & Conservative & 6 months \\
\hline d'Ettorre (2009) & 1 & Secondary & Thoracic & Conservative & Conservative & Not specified \\
\hline de Koning (2008) & 1 & Secondary & Lumbar & $\begin{array}{l}\text { Removal and } \\
\text { bypass }\end{array}$ & Debridement & 7 months \\
\hline Faccenna (2013) & 1 & Secondary & Lumbar & Conservative & Drainage & 48 months \\
\hline Laser (2011) & 2 & Secondary & $\begin{array}{l}1 \times \text { lumbar; } 1 \times \text { not } \\
\text { reported }\end{array}$ & $\begin{array}{l}2 \times \text { removal and } \\
\text { bypass }\end{array}$ & $2 \times$ conservative & 3-6 months \\
\hline Lowe (2012) & 1 & Secondary & Lumbar & Conservative & Conservative & $\begin{array}{l}\text { Lifelong oral antibi- } \\
\text { otics }\end{array}$ \\
\hline Mandegaran (2018) & 9 & Secondary & Lumbar & $\begin{array}{l}4 \times \text { removal and } \\
\text { bypass; } 5 \times \text { con- } \\
\text { servative }\end{array}$ & $\begin{array}{c}1 \times \text { debridement } \\
\text { and fusion; } 4 \times \\
\text { drainage; } 5 \times \\
\text { conservative }\end{array}$ & Not specified \\
\hline Mavrogenis (2014) & 1 & Secondary & Lumbar & Conservative & Conservative & 12 months \\
\hline Santbergen (2012) & 1 & Secondary & Lumbar & $\begin{array}{l}\text { Removal and } \\
\text { bypass }\end{array}$ & Conservative & 6 months \\
\hline
\end{tabular}


with a mixture of cancellous bone, gentamicin and vancomycin. The remaining defects in the adjacent vertebrae and disc space after cage positioning were also supplemented with this mixture. Alternatively, titanium cages or mesh cages made of titanium could be used instead. The cages were also filled with the above-mentioned mixture.

In cases where a mycotic aortic aneurysm was present in combination with spondylodiscitis, a custom-made aortic stent graft was first implanted into the infected abdominal aortic aneurysm [4], and then, the posterior spine was treated in the manner described above with a two-stage procedure.

We analysed the demographic data, the diagnostic and therapeutic strategies, the isolated pathogens, the duration and substance of the antibiotic therapy and the method of application. MRI-specific features were described focusing on epidural abscesses. We also analysed possible sources of infection as an explanation for the pathogenesis within the last 6 months before occurrence of the infection. As a clinical parameter, the numeric rating scale (NRS) was recorded preoperatively and at the last follow-up (FU). The following parameters were selected to define the recovery of the infection: FU time of at least 6 months after treatment with unremarkable inflammation parameters (white blood cells, C-reactive protein) after therapy and/or normal control PET or MRI examinations. In addition, peri- and postoperative complications were investigated. The Cobb angle was measured pre- and postoperatively as radiological criteria at the last FU. Additionally, possible cage subsidence was analysed [14]. For those patients who died, the last recorded NRS score or X-ray image was used for Cobb measurements after therapy initiation.

\section{Data presentation}

Data are presented as the mean \pm standard deviation (SD) and range. Due to inhomogeneous follow-up examinations, these data are presented as the median and range. Based on the small sample size and related missing power, statistical analyses were avoided to neither over- nor underestimate the results (Figs. 1, 2. 3, 4, 5).

\section{Results}

Fifteen patients (one female: 14 males) with a mean age of $73.3 \pm 9.7$ years (range 59-92) were identified and treated for primary and secondary infections of aortic stent grafts and simultaneous infection of the vertebral column region with spondylodiscitis from 583 patients treated with EVAR at our centre for AAA between 2012 and 2019. Nine patients $(1.5 \%)$ treated with EVAR in our centre were diagnosed with secondary stent graft infection during follow-up, and a

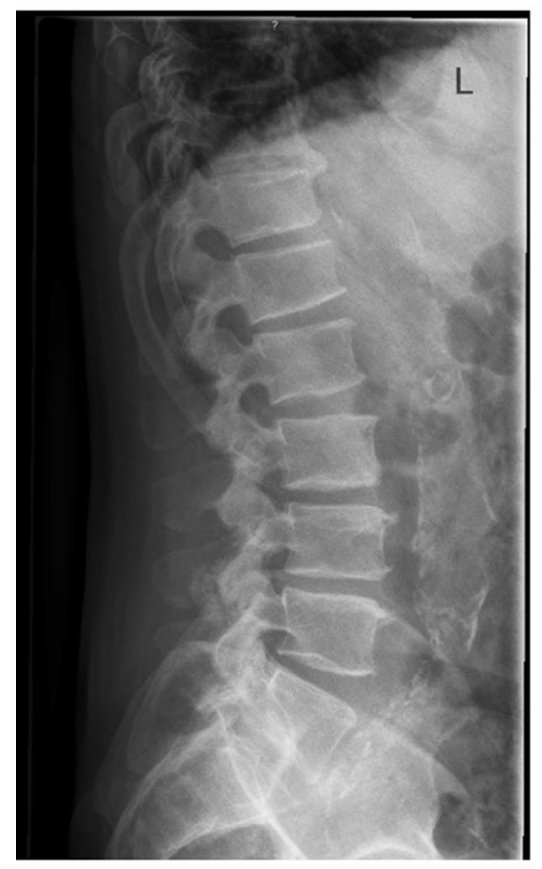

b

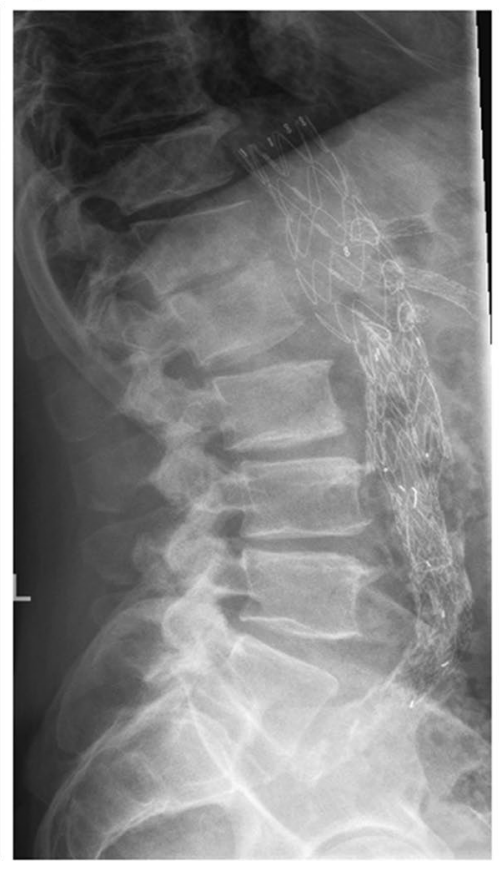

C

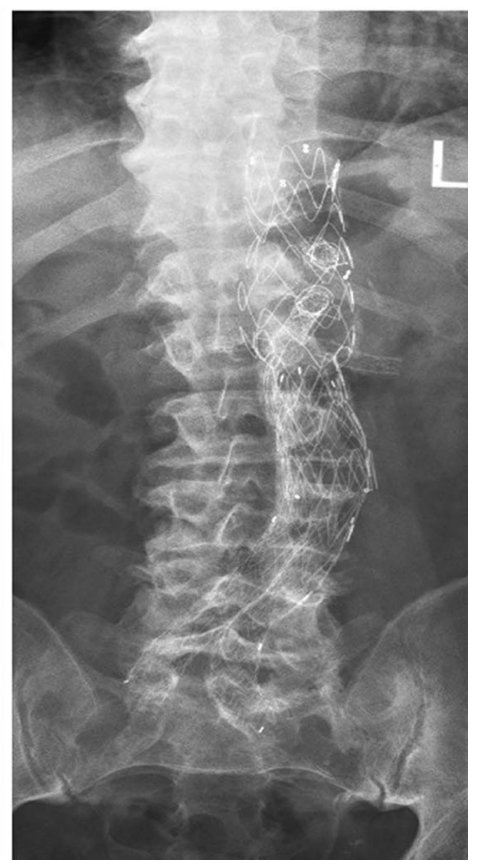

Fig. 1 a A native lateral X-ray 3 weeks before EVAR. The extent of the covered ruptured aortic aneurysm is clearly visible. b, c Native anterior-posterior view 6 months after repair of the covered ruptured mycotic aneurysm in the thoracoabdominal aorta (Crawford IV) with an aortobiiliacal fenestrated stent graft. The patient had signs of sepsis with identification of Pseudomonas aeruginosa in blood culture. The ground and cover plate showed signs of destruction in T12/L1 as signs of spondylodiscitis and segmental kyphosis 

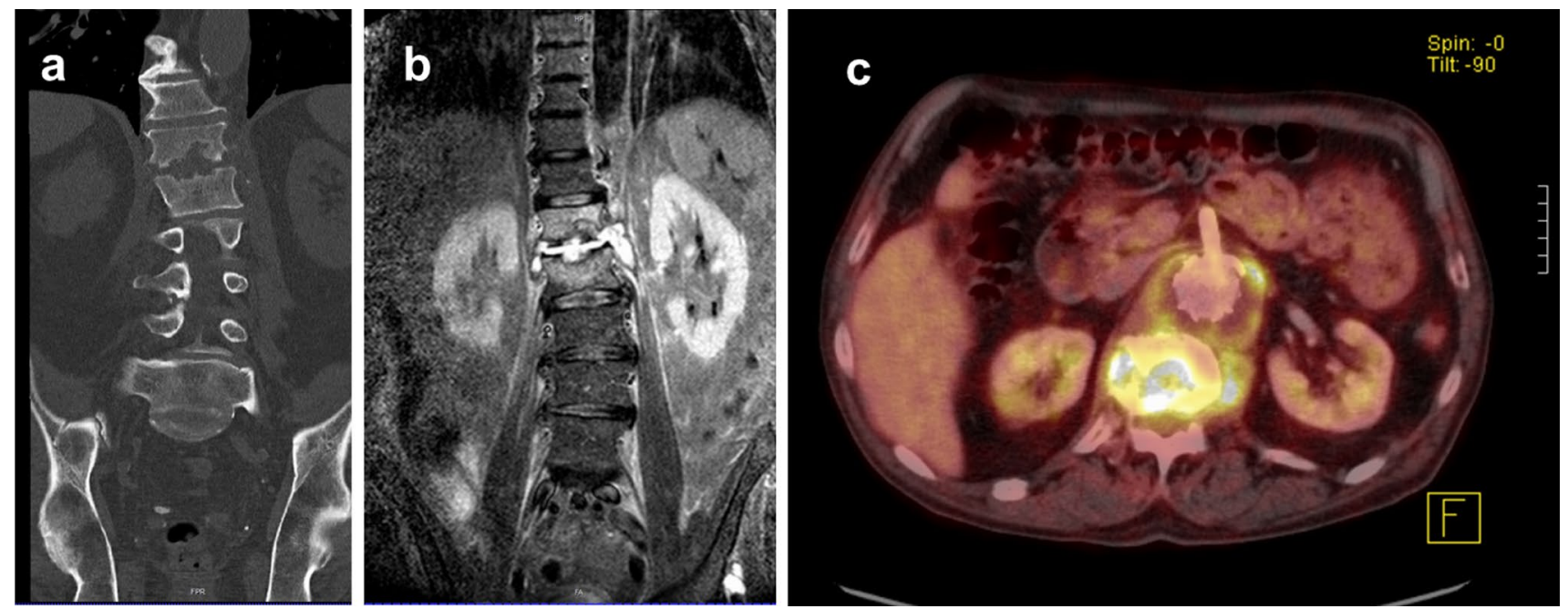

Fig. 2 a Severe bony defect in the T12/L1 region according to spondylodiscitis in coronal CT imaging. b Lateral extension of the psoas abscess on both sides in the turbo inversion recovery magnitude

(TIRM) MRI sequence. $\mathbf{c}$ Direct contact between the infected native aortic sac and the spondylodiscitis region in the axial image from the 18 F-FDG-PET examination
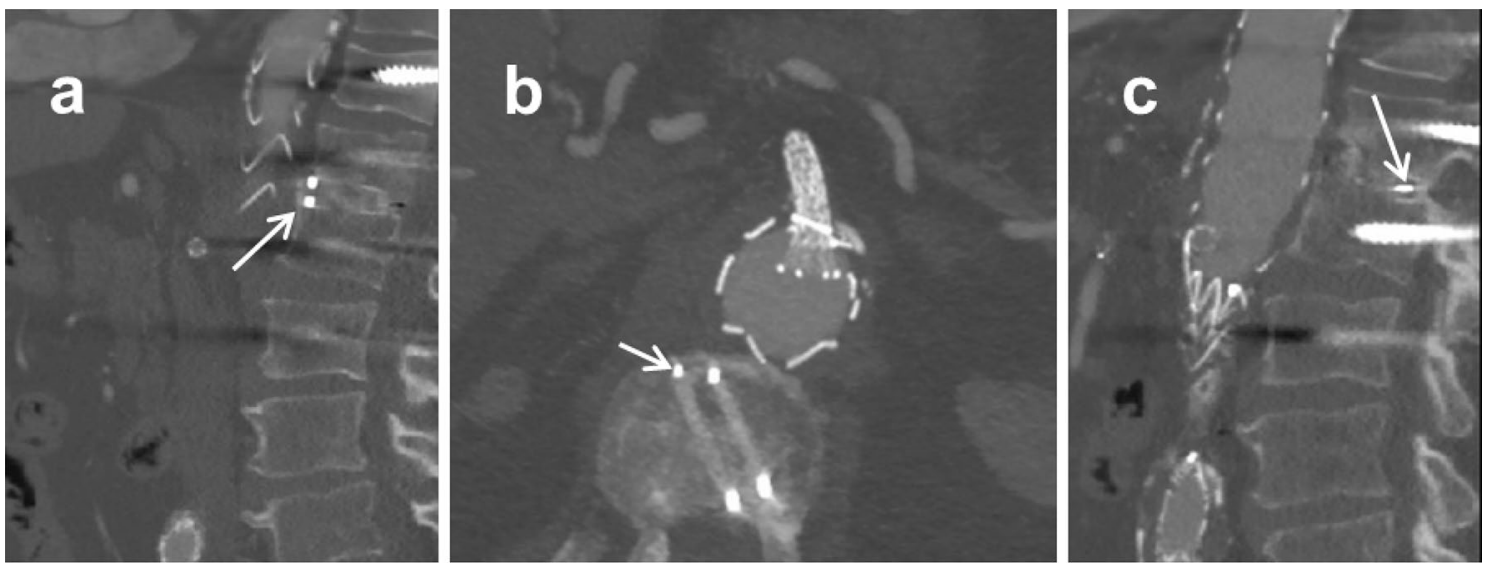

Fig. 3 a-c A CT control examination one year postoperatively. Figure a shows sagittal CT imaging with bony fusion of the T12/L1 segment. The cage was subsided by $3 \mathrm{~mm}$ compared to the pre-CT examination results. a, b Close relationship between the aortic stent graft and the

three patients were referred to us with secondary stent graft infection after EVAR in an external hospital. Four patients were treated with EVAR for MAA primarily. The median interval from EVAR to the first imaging features of graft infection and spondylodiscitis in secondary infected vascular prostheses after EVAR was 12.4 (range 6.1-32.8 months). Infections 6 months prior to EVAR infection and related spondylodiscitis were recorded as potential causes of infection. Here, surgical interventions of the abdominal and urogenital regions in 6 patients and tumour surgeries in 5 patients were the dominant causes. The remaining patients suffered from pneumonia, mitral valve endocarditis, venous access device infection and EVAR endoleak (each $n=1$ ). infected segment. Compared to Fig. 2c, the distance between the aortic stent graft and the spinal column is no longer visible. The white arrows mark the cage position of the titanium-coated oblique PEEK cage

No spinal surgery or injection in the area of the spine within the investigated interval was found. In 12 patients, the diagnosis of graft infection and spondylodiscitis was confirmed by PET/CT. In 3 of 9 patients, additional MRI detected an epidural abscess. All three cases of epidural abscesses were surgically opened and drained through a posterior approach. Psoas abscesses occurred in 7 patients. All identified psoas abscesses were in direct contact with the psoas abscess and were drained (for example, Fig. 6). In six cases, the psoas abscess was split and drained via the posterior approach. In 12 cases, the native aneurysm sac with surrounding paraaortic and paraspinal abscesses had contact with the infected vertebral region. For the remaining 3 cases, the infection 
Fig. 4 a, b Postoperative X-ray 24 months after surgery with recovery of the infection without recurrence
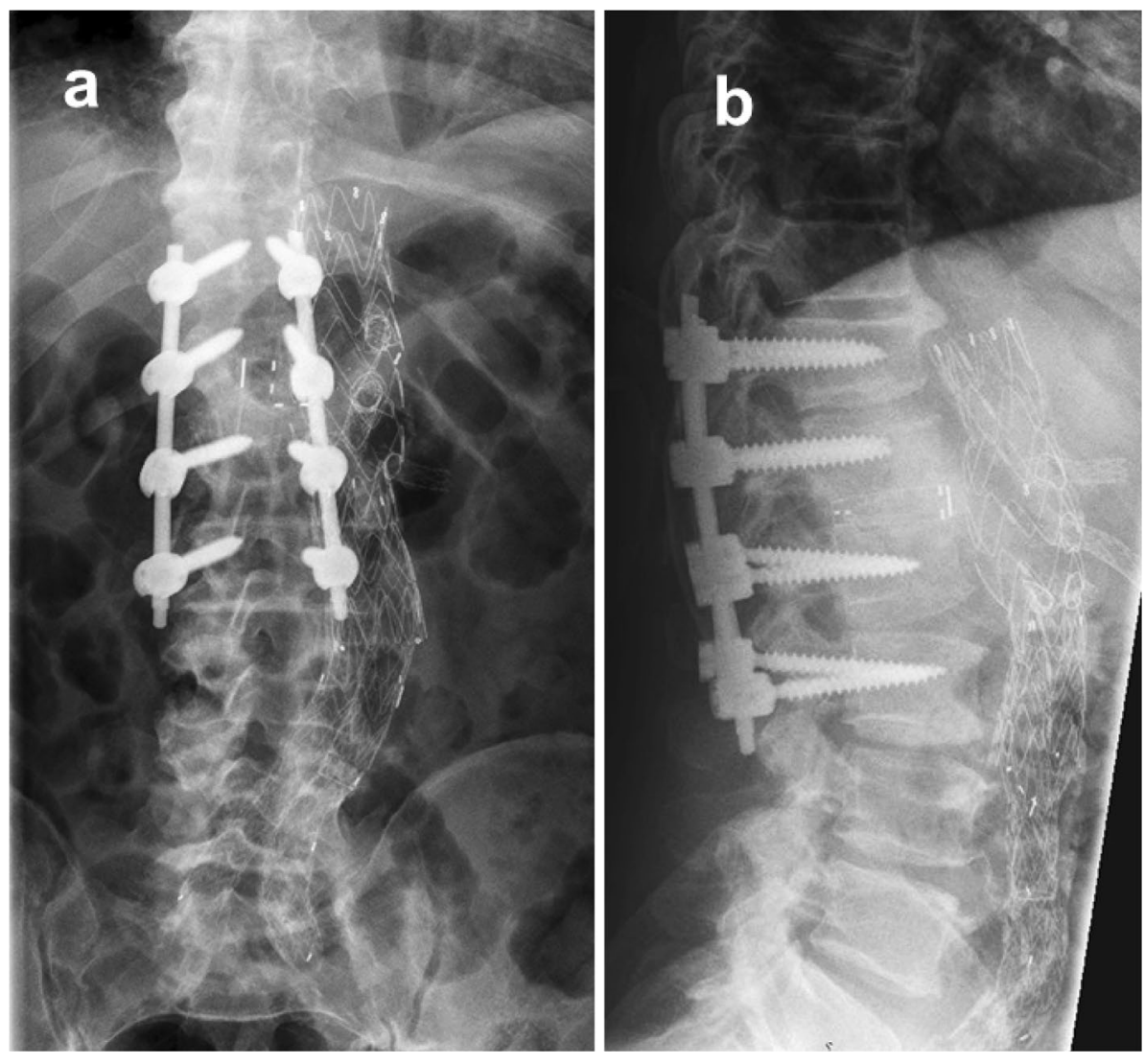

was in vicinity to the spondylodiscitis region, but had no direct contact.

The pathogen was identified in 11 cases. The most frequent pathogens were Staphylococcus epidermidis and Staphylococcus aureus (Table 2), each found in 3 cases. Antibiotic therapy was carried out individually for each patient in consultation with the microbiological department and the department of infectious diseases. Antibiotics were administered initially intravenously and, if possible, orally after 2 weeks (Table 2). In 7 patients, antibiotics were administered first intravenously for two weeks followed by oral administration for six weeks. Five patients were treated for 7 weeks or longer. In all four cases without germ detection, an antibiotic from the lincosamide group was administered based on the local resistance situation with coverage of the Gram-positive bacterial spectrum. One patient received antifungal therapy (50-400 mg fluconazole adapted for renal function) for 8 weeks due to the detection of Candida albicans. One patient received oral antibiotics for 6 weeks. One patient who died after 6 weeks received antituberculostatic therapy at this time.

According to the American Society of Anesthesiologists (ASA) classification system, all patients suffered at least from a severe systemic disease.

CT-assisted drainage of psoas abscesses was performed preoperatively in two patients with extensive abscess formation. Spondylodiscitis was treated in 8 patients using a posterior approach with debridement of the intervertebral disc and intersomatic fusion with a titan-coated PEEK cage filled with allogenic bone and a mixture of vancomycin and gentamicin. In the other two patients, who were treated with the posterior-anterior approach, the ventral defect was too severe, making posterior cage insertion impossible (Fig. 6). In one patient, the MAA was treated preoperatively with EVAR and a custom-made prosthesis. The other patient had a secondary infected stent graft. In both patients, only the spinal column was surgically addressed from the anterior approach.

In the two patients who underwent the anterior approach, the secondary infected stent was removed, and an extra-anatomic silver-coated bypass was implanted. Here, the aortic sac was in direct contact with the area of spondylodiscitis. In both cases, the patients were in a septic condition. In the same session, the psoas abscess was drained, the intervertebral disc was removed, and a cage was implanted.

Overall complications were recognized in 5 patients, of which complications associated with surgery occurred in 3 patients. Postoperative complications occurred in 2 patients with wound healing disorders after the posterior procedure, which were revised during the hospital stay.

The median follow-up time was 8 months (range 1-47 months). Three patients had a follow-up 
Fig. 5 A 63-year-old patient was admitted with a penetrating ulcer of the aorta (PAU; a, white arrow) following EVAR two years prior. In the CT examination (a), direct contact (black arrows) of the PAU and lumbar vertebrae 2 and 3 treated with balloon kyphoplasty

1 month before admission and a psoas abscess were visualized (asterisk). Spondylodiscitis was treated with antibiotics, and a drainage tube was inserted into the psoas abscess. No pathogen could be isolated. The PAU was treated by insertion of a custommade thoracoabdominal prosthesis of the aorta. Eight months later, persistent spondylodiscitis with spondylitis and bony destruction was visible on PETCT (b, white arrows). Thus, a two-stage posterior-anterior surgical approach with removal of the cement was performed (c)
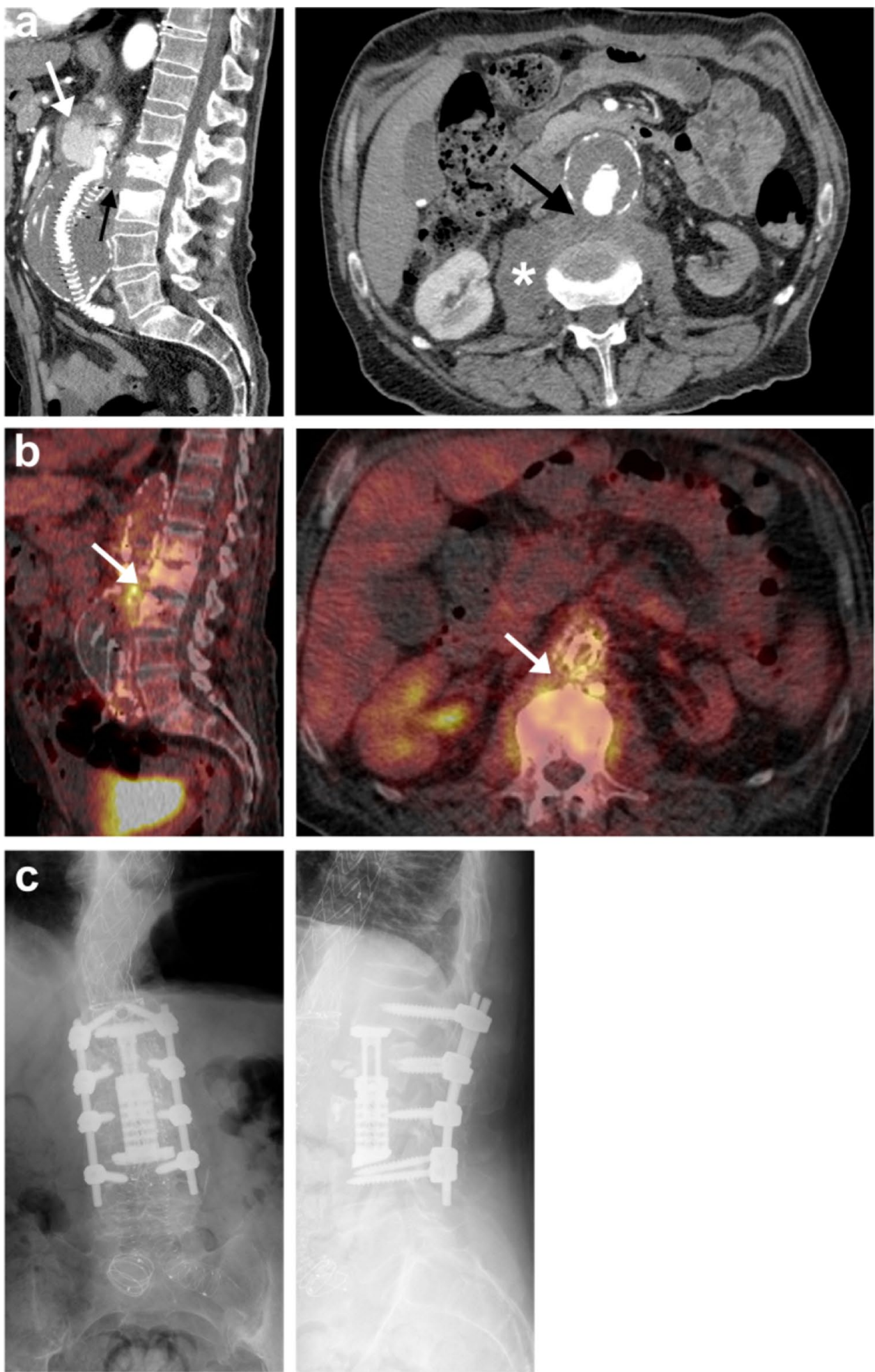

posterior-anterior surgical treatment of the spine, antifungal therapy with fluconazole was administered for 8 weeks after the pathogen was confirmed to be Candida albicans. The dosage was adjusted according to the limited renal retention parameters on a daily basis. One patient (No. 7) died after anterior revision of the aorta with silver-coated only $<3$ months. During the follow-up, the overall mortality rate was $27 \%(n=4)$. One patient (No. 4) with a secondary tuberculosis-infected aortic stent graft died after conservative treatment. One patient (No. 6) died in the hospital 80 days after the surgical spine procedure. This patient presented with mycotic spondylodiscitis. After two-stage 


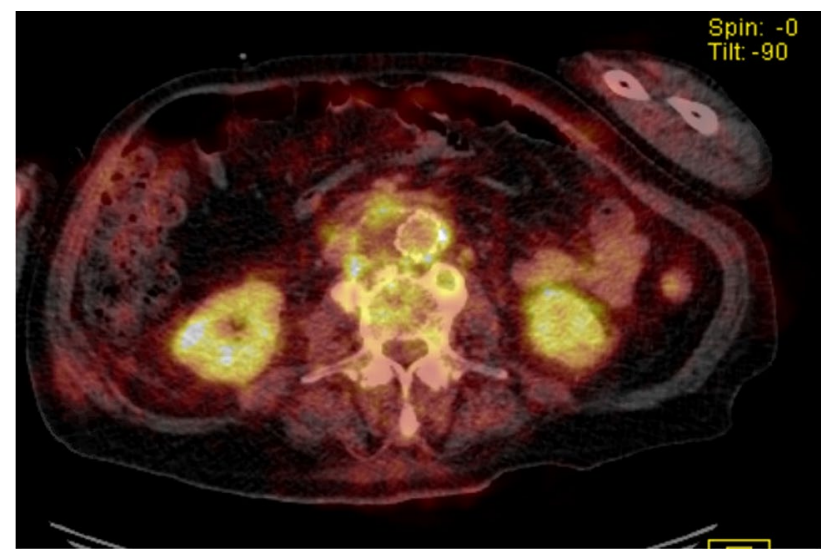

Fig. 6 Florid spondylodiscitis at the LWK 1/2 level with melting in the right iliopsoas muscle on 18 F-FDG-PET-CT. Inflammatory signs at the transformed thrombosed aortic aneurysm sac at the level of the renal hilum with pathologically increased glucose metabolism and additional inflammatory reactions in the properly contrasted, glucose metabolism-active aortic prosthesis

bypass and one-stage removal of the disc with stabilization 3 months after discharge. One patient (No. 13) died after ventral vascular revision with bypass and debridement of the intervertebral disc 4 weeks after discharge. The mean hospital stay was $38 \pm 24$ days. Pain intensity scores on the NRS improved from $8.4(3.2-8.3)$ to $3.1(1.3-6.7)$ at the last FU. Radiologically, the Cobb angle improved from $-14.7^{\circ}$ preoperatively to $-2.4^{\circ}$. Afterwards, in two patients, cage subsidence was detected without clinical symptoms or signs of fusion (Fig. 3). Recovery from infection was confirmed in 10 patients. The recovery from infection could be confirmed in 5 patients by laboratory parameters within their specific reference frame, in 2 patients by PET-CT and MRI examinations and in one patient by CT examination [12].

\section{Discussion}

The combination of spondylodiscitis derived from a primary infection after EVAR treatment for a mycotic aortic aneurysm (MAA) or from secondary infected aortic grafts after endovascular aneurysm repair (EVAR) is a rare complication. However, the incidence of infection after EVAR infection is low, and a correspondingly high mortality rate has been described $[10,15,16]$. The risk of infection during the EVAR procedure itself was estimated in a small case series to be $0.4-5 \%$, whereby skin contamination is one of the main reasons for contamination by micro-organisms [17]. Our 1.5\% incidence of stent graft infection compares well with the published rate of $0.4-5 \%$ of endograft infection [18]. After insertion of an endoluminal prosthesis, the recovery period can be up to 6 years [19], ${ }^{13}$. During this time, a pseudo-intima is formed, protecting the graft permanently. This period also represents a very vulnerable period in which parts of the prosthesis remain susceptible to bacterial colonization [20]. Smeds et al. reported a high incidence of missing intima integration of very large vascular constructs of the aorta resulting in permanent infection [21]. In our analysis, we found several possible foci for infections of aortic stent grafts. We limited the time period (6 months) before detection of endograft infections. In some studies, even infections dating back to 12 months have been reported as possible causes [12].

In a case series of 9 patients focusing on imaging features, Mandegaran and colleagues described a spreading infection from the infected native aortic sac around the EVAR. Only in one case did they find no direct contact and suspicion of haematogenic spreading. For their theory of pathogenesis, the authors concluded that the anterior part of the vertebral bodies and the intervertebral disc had direct contact with the native sac abscess. Hence, the anterior structures showed more inflammatory changes than the dorsal elements of the affected segment [11]. We identified direct contact between the infected aortic sac and the affected spinal segment in 12 patients (Fig. 5), supporting the theory of a direct spreading infection, as suggested by Madrigaran et al.

The aim of vascular graft infection therapy is to remove the source of infection without serious perfusion disturbances $[2,9]$. However, there is a consensus that infected endografts should be removed if tolerated by the patient's condition. There are different possible treatment approaches for aortic stent graft infection. Removal of the infected stent graft and in situ reconstruction with biological material is recommended for patients with secondary stent graft infection who are fit for surgery, since this technique has the lowest reinfection rate. Conservative treatment with continuous antibiotics or drainage of the infection without removal of stent graft is recommended for surgical high-risk patients [22]. In a systematic review and meta-analysis by Li et al. (402 patients with infections after EVAR or TEVAR), the survival probability of surgically treated patients was better than that of conservative patients (58\% vs. 33\%) [23]. However, there is no consensus on surgical treatment of MAA because of the complexity of the disease and lack of obvious superiority of any single treatment method. Open surgical repair with resection of the aneurysm, extensive local debridement and revascularization by in situ reconstruction with biological vascular grafts, allografts and recently added self-made xenopericardial tubes or extra-anatomic bypass was the dominant surgical technique prior to 2010, shifting to EVAR thereafter. A recent European multicentre study on MAAs showed that endovascular treatment of MAA is feasible and, for most patients, a durable treatment option [4]. After reviewing the current literature, the combination of spondylodiscitis with continuous tissue infected aortic 


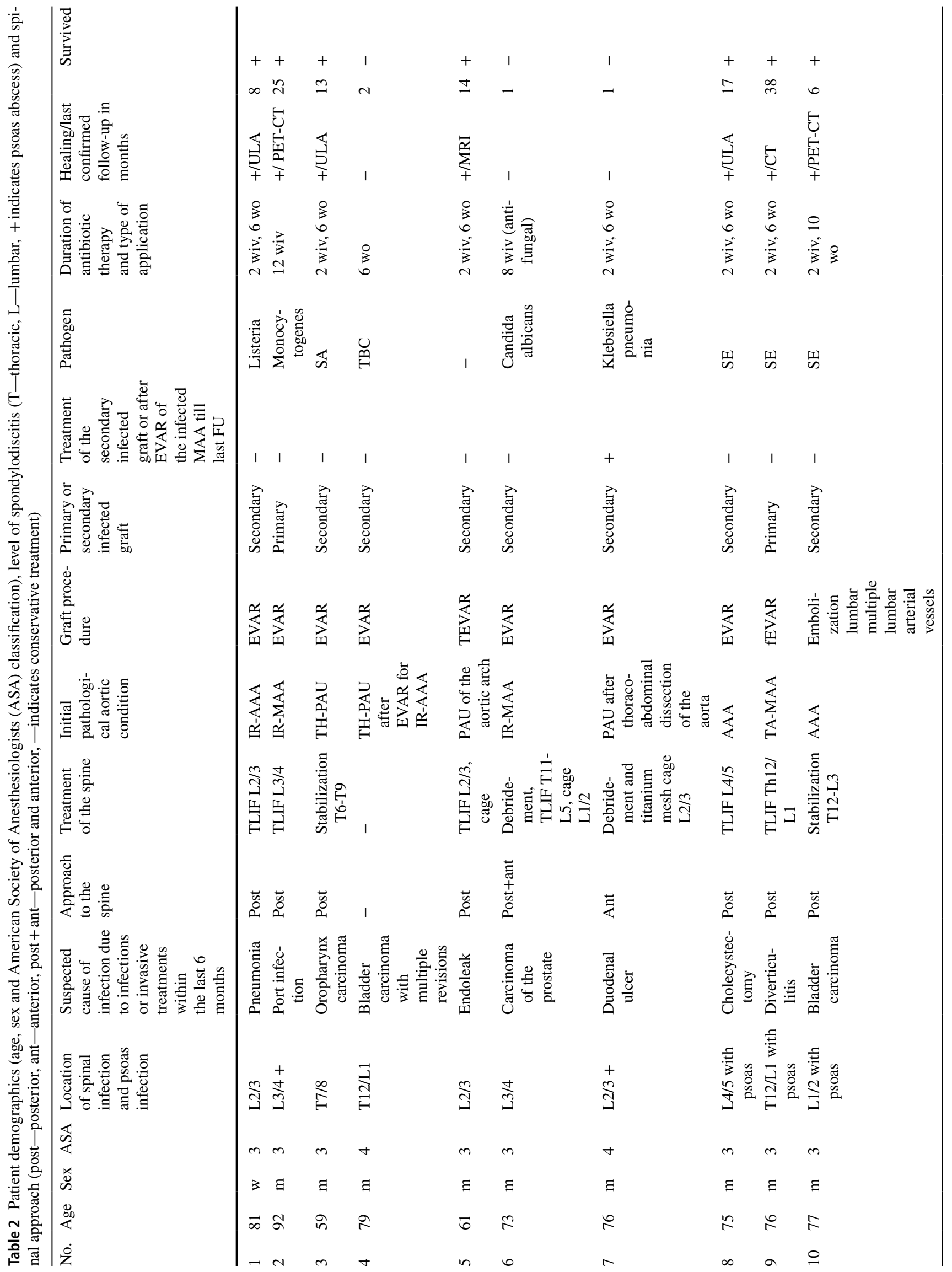




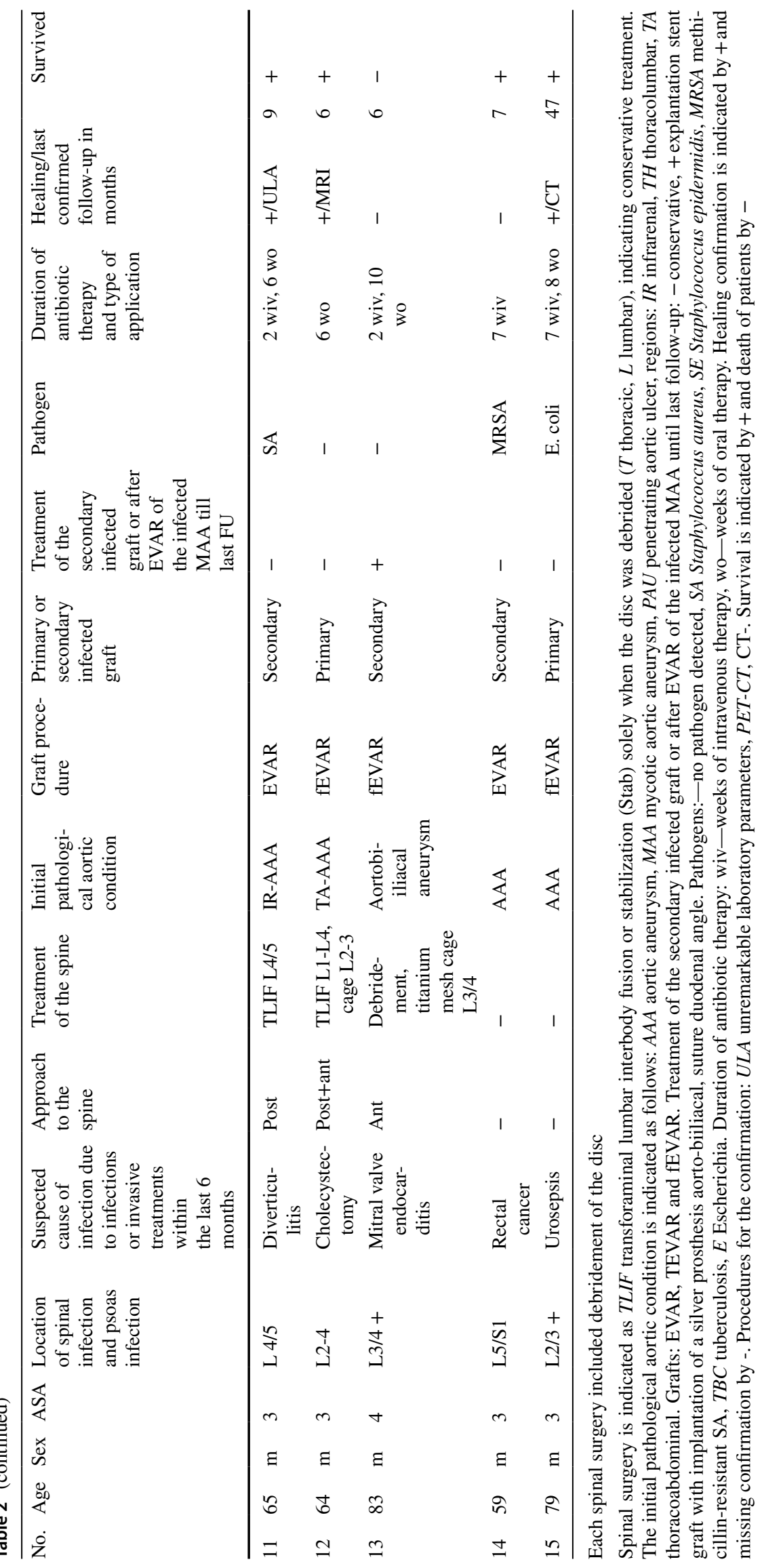


endografts or MAAs, there is no recommendation for a specific strategy due to the heterogeneous available data. A review by Megaloikonomos and colleagues of 14 patients with infected aortic prostheses (8 after EVAR/7 after open vascular prostheses) recommended that patients should be informed about the high mortality risk of up to $20 \%$ and concluded that a conservative therapy regimen with prolonged antibiotic treatment and close follow-up should be performed in seriously sick patients [12]. 30-Day mortality rate of $8 \%-39 \%$ and amputation rates of $0-2 \%$ were reported after removal of infected stent graft and in situ reconstruction of the aorta. Patients managed with antimicrobial therapy alone have a 30-day mortality as high as $63.3 \%$ (PMID: 27,289,529). We found a comparable mortality rate of $27 \%$ in our cohort.

The development of non-specific spondylodiscitis is associated with a large number of variables. However, there are patient-associated and operation-related risk factors [24-26]. In our analysis, we had no patients with spine surgery, and the patients had not received any injection in the area of the spine within the investigated interval. An infection per continuitatem originating from the adjacent native aortic sac may also be probable in our patient population, which would correspond to Mandegran's theory of pathogenesis [11].

Lu et al. showed a 1-year survival rate of $75.5 \%$ in a retrospective analysis of 102 patients with spondylodiscitis due to a catheter infection during haemodialysis. In $75 \%$ of the patients, the infected catheter was removed, and in 54\%, the region of spondylodiscitis was debrided and stabilized. In our cohort, 13 patients were treated surgically due to spinal instability, extensive destruction or disease progression despite ongoing antibiotic treatment. However, these are only studies with a low level of evidence (III-V) [27-29]. In a systematic review, Herren et al. [5] highlighted the indications for surgical management as follows:

Sepsis and presepsis;

Relevant neurological deficits;

Intraspinal empyema;

Presence of a ventral paravertebral abscess $>2.5 \mathrm{~cm}$;

Not responding to antibiotic therapy (no decrease in laboratory inflammatory parameters);

Progressive instabilities and deformities with and without pain.

Infections can result in destruction of the affected segments, causing destabilization. However, the indications for stabilization we used were based on the following criteria [5]:

Segmental kyphosis $\left(>15^{\circ}\right)$; Vertebral body collapse $>50 \%$; Translation $>5 \mathrm{~mm}$.
Conservative therapy can generally be used in most cases of pyogenic or specific spondylodiscitis [30]. Non-surgical therapy can be considered based on the following criteria [31]:

Only minor/mild clinical symptoms are present; No neurological deficits;

Missing or only slight bony destruction is present.

The surgical risk is too serious.

Nevertheless, there is still no clear consensus on the duration of antibiotic therapy. The IDSA guidelines recommend a 6-week therapy duration to be adequate for most patients with pyogenic native spondylodiscitis [24]. In our patients, the length of the antibiotic treatment was very specific in all cases, and treatment was performed after consultation with microbiologists and the department of infectious diseases.

The retroperitoneal space has low resistance to infection. As a result, infections can spread widely with prolonged symptoms and delayed diagnoses. From an anatomical view, there are two different foci in co-infections of aortic stent grafts and the spinal column; thus, there is a risk that the foci will maintain each other. Furthermore, there are different types of tissues, such as bone, intervertebral disc tissue and vascular structures, with infected foreign bodies, which must be considered when administering antibiotics with regard to the corresponding tissue absorption.

The effect of local debridement, and thus abscess relief, remains unclear. However, we observed recovery from infection in the majority of patients after debridement and stabilization. At this point, the question arises whether abscess flushing using a CT-supported drainage insert for decompression of abscesses would be useful to reduce the infection load, to isolate pathogens and to start specific antibiotic therapy [32]. In our cohort, only two patients received CTsupported drainage preoperatively. In this context, we would like to point out again that a clear differentiation between the infected native aortic sac and paravertebral abscess is not always easy to differentiate. One patient in our cohort developed a mycotic aneurysm with florid spondylodiscitis and a large psoas abscess (Fig. 6). In a retrospective study, Yang et al. treated 32 patients endoscopically with debridement and drainage (81.5\% healed, 38-month follow-up) [33] .

\section{Limitations of the study}

The number of patients in this single-centre experience was small for making statistical statements. Due to its rarity, it is very specific and patients have several comorbidities, and relevant comparison groups are missing in the current literature. The time limitation to recovery from infection after 6 months does not indicate long-term therapeutic success, 
especially with the risk of EVAR reinfection in the group of conservatively treated patients.

\section{Conclusion}

This is the largest case series of patients with spondylodiscitis associated with infected aortic stent grafts. Close interdisciplinary cooperation pre-, inter- and postoperatively is obligatory in this highly specific patient population and requires the consideration of individual therapy. The posterior approach with debridement and stabilization of spondylodiscitis resulted in short-term recovery without serious complications, thus offering a therapeutic strategy.

Funding Open Access funding provided by Projekt DEAL.

\section{Compliance with ethical standard}

Conflict of interest None.

Open Access This article is licensed under a Creative Commons Attribution 4.0 International License, which permits use, sharing, adaptation, distribution and reproduction in any medium or format, as long as you give appropriate credit to the original author(s) and the source, provide a link to the Creative Commons licence, and indicate if changes were made. The images or other third party material in this article are included in the article's Creative Commons licence, unless indicated otherwise in a credit line to the material. If material is not included in the article's Creative Commons licence and your intended use is not permitted by statutory regulation or exceeds the permitted use, you will need to obtain permission directly from the copyright holder. To view a copy of this licence, visit http://creativecommons.org/licenses/by/4.0/.

\section{References}

1. Berger P, Vaartjes I, Moll FL, de Borst GJ, Blankensteijn JD, Bots ML (2015) Cumulative incidence of graft infection after primary prosthetic aortic reconstruction in the endovascular era. Eur J Vasc Endovasc Surg 49(5):581-585. https://doi.org/10.1016/j. ejvs.2015.01.001

2. Ducasse E, Calisti A, Speziale F, Rizzo L, Misuraca M, Fiorani P (2004) Aortoiliac stent graft infection: current problems and management. Ann Vasc Surg 18(5):521-526. https://doi.org/10.1007/ s10016-004-0075-9

3. Hobbs SD, Kumar S, Gilling-Smith GL (2010) Epidemiology and diagnosis of endograft infection. J Cardiovasc Surg 51(1):5-14

4. Sörelius K, Wanhainen A, Furebring M, Björck M, Gillgren P, Mani K (2016) Nationwide study of the treatment of mycotic abdominal aortic aneurysms comparing open and endovascular repair. Circulation 134(23):1822-1832. https://doi.org/10.1161/ CIRCULATIONAHA.116.024021

5. Herren C, Jung N, Pishnamaz M, Breuninger M, Siewe J, Sobottke R (2017) Spondylodiscitis: diagnosis and treatment options. Deutsches Arzteblatt Int 114(51-52):875-882. https:// doi.org/10.3238/arztebl.2017.0875
6. Blanch M, Berjón J, Vila R, Simeon JM, Romera A, Riera S, Cairols MA (2010) The management of aortic stent-graft infection: endograft removal versus conservative treatment. Ann Vasc Surg 24(4):554.e1-5. https://doi.org/10.1016/j.avsg.2009.11.003

7. d'Ettorre G, Ceccarelli G, Zaffiri L, Falcone M, Mastroianni CM, Venditti M, Vullo V (2009) Infectious aortitis and spondylodiscitis in patients with endovascular stents. Minerva Med 100(2): $167-170$

8. de Koning HD, van Sterkenburg SMM, Pierie MEN, Reijnen MMPJ (2008) Endovascular abdominal aortic aneurysm repair complicated by spondylodiscitis and iliaco-enteral fistula. J Vasc Surg 47(6):1330-1332. https://doi.org/10.1016/j.jvs.2007.12.047

9. Laser A, Baker N, Rectenwald J, Eliason JL, Criado-Pallares E, Upchurch GR (2011) Graft infection after endovascular abdominal aortic aneurysm repair. J Vasc Surg 54(1):58-63. https://doi. org/10.1016/j.jvs.2010.11.111

10. Lowe C, Chan A, Wilde N, Hardy S (2012) Infected endovascular aneurysm repair graft complicated by vertebral osteomyelitis. J Vasc Surg 56(3):826-828. https://doi.org/10.1016/j. jvs.2012.03.268

11. Mandegaran R, Tang CSW, Pereira EAC, Zavareh A (2018) Spondylodiscitis following endovascular abdominal aortic aneurysm repair: imaging perspectives from a single centre's experience. Skeletal Radiol 47(10):1357-1369. https://doi.org/10.1007/s0025 6-018-2939-z

12. Megaloikonomos PD, Antoniadou T, Dimopoulos L, Liontos M, Igoumenou V, Panagopoulos GN, Giannitsioti E, Lazaris A, Mavrogenis AF (2017) Spondylitis transmitted from infected aortic grafts: a review. J Bone Joint Infect 2(2):96-103. https://doi. org/10.7150/jbji. 17703

13. Santbergen B, Vriens PHWE, de Lange WCM, van Kasteren MEE (2013) Combined infection of vertebroplasty and aortic graft after intravesical BCG treatment. BMJ Case Rep. https:// doi.org/10.1136/bcr-2012-008161

14. von der Hoeh NH, Voelker A, Hofmann A, Zajonz D, Spiegl UA, Jarvers J-S, Heyde C-E (2018) Text Pyogenic Spondylodiscitis of the Thoracic Spine: Outcome of 1-Stage Posterior Versus 2-Stage Posterior and Anterior Spinal Reconstruction in Adults. World neurosurgery 120:e297-e303. https://doi.org/10.1016/j. wneu.2018.08.055

15. Sharif MA, Lee B, Lau LL, Ellis PK, Collins AJ, Blair PH, Soong CV (2007) Prosthetic stent graft infection after endovascular abdominal aortic aneurysm repair. J Vasc Surg 46(3):442-448. https://doi.org/10.1016/j.jvs.2007.05.027

16. Argyriou C, Georgiadis GS, Lazarides MK, Georgakarakos E, Antoniou GA (2017) Endograft infection after endovascular abdominal aortic aneurysm repair: a systematic review and meta-analysis. J Endovasc Therapy 24(5):688-697. https://doi. org/10.1177/1526602817722018

17. Coselli JS, Spiliotopoulos K, Preventza O, de la Cruz KI, Amarasekara H, Green SY (2016) Open aortic surgery after thoracic endovascular aortic repair. Gen Thorac Cardiovasc Surg 64(8):441-449. https://doi.org/10.1007/s11748-016-0658-8

18. Shukuzawa K, Ohki T, Maeda K, Kanaoka Y (2019) Risk factors and treatment outcomes for stent graft infection after endovascular aortic aneurysm repair. J Vasc Surg 70(1):181-192. https://doi. org/10.1016/j.jvs.2018.10.062

19. Capoccia L, Menna D, Montelione N, Tarantino R, Marruzzo D, Sbarigia E, Speziale F (2014) Abdominal aortic rupture and spondylodiscitis: emergent EVAR and staged spinal fixation. Ann Vasc Surg 28(5):1312.e7-11. https://doi.org/10.1016/j. avsg.2013.08.029

20. Faccenna F, Alunno A, Castiglione A, Carnevalini M, Venosi S, Gossetti B (2013) Large aortic pseudoaneurysm and subsequent spondylodiscitis as a complication of endovascular treatment of 
iliac arteries. Thorac Cardiovasc Surg 61(7):606-609. https://doi. org/10.1055/s-0033-1333843

21. Smeds MR, Duncan AA, Harlander-Locke MP, Lawrence PF, Lyden S, Fatima J, Eskandari MK (2016) Treatment and outcomes of aortic endograft infection. J Vasc Surg 63(2):332-340. https:// doi.org/10.1016/j.jvs.2015.08.113

22. Chakfé N, Diener H, Lejay A, Assadian O, Berard X, Caillon J, Fourneau I, Glaudemans AWJM, Koncar I, Lindholt J, Melissano G, Saleem BR, Senneville E, Slart RHJA, Szeberin Z, Venermo M, Vermassen F, Wyss TR, Esvs GC, de Borst GJ, Bastos Gonçalves F, Kakkos SK, Kolh P, Tulamo R, Vega de Ceniga M, Document R, von Allmen RS, van den Berg JC, Debus ES, Koelemay MJW, Linares-Palomino JP, Moneta GL, Ricco J-B, Wanhainen A (2020) Editor's choice - european society for vascular surgery (ESVS) 2020 clinical practice guidelines on the management of vascular graft and endograft infections. Eur J Vasc Endovasc Surg 59(3):339-384. https://doi.org/10.1016/j.ejvs.2019.10.016

23. Li HL, Chan YC, Cheng SW (2018) Current evidence on management of aortic stent-graft infection: a systematic review and metaanalysis. Ann Vasc Surg 51:306-313. https://doi.org/10.1016/j. avsg.2018.02.038

24. Berbari EF, Kanj SS, Kowalski TJ, Darouiche RO, Widmer AF, Schmitt SK, Hendershot EF, Holtom PD, Huddleston PM, Petermann GW, Osmon DR (2015) Executive summary: 2015 infectious diseases society of America (IDSA) clinical practice guidelines for the diagnosis and treatment of native vertebral osteomyelitis in adults. Clin Infect Dis 61(6):859-863. https:// doi.org/10.1093/cid/civ633

25. Cheung WY, Luk KDK (2012) Pyogenic spondylitis. Int Orthop 36(2):397-404. https://doi.org/10.1007/s00264-011-1384-6

26. Fantoni M, Trecarichi EM, Rossi B, Mazzotta V, Di Giacomo G, Nasto LA, Di Meco E, Pola E (2012) Epidemiological and clinical features of pyogenic spondylodiscitis. Eur Rev Med Pharmacol Sci 16(Suppl 2):2-7

27. Hadjipavlou AG, Katonis PK, Gaitanis IN, Muffoletto AJ, Tzermiadianos MN, Crow W (2004) Percutaneous transpedicular discectomy and drainage in pyogenic spondylodiscitis. Eur Spine J 13(8):707-713. https://doi.org/10.1007/s00586-004-0699-z

28. Tschoeke SK, Kayser R, Gulow J, Nvd Hoeh, Gv Salis-Soglio, Heyde C (2014) Single-stage epidural catheter lavage with posterior spondylodesis in lumbar pyogenic spondylodiscitis with multilevel epidural abscess formation. J Neurol Surg Part A Central Eur Neurosurg 75(6):447-452. https://doi. org/10.1055/s-0034-1368684

29. Duarte RM, Vaccaro AR (2013) Spinal infection: state of the art and management algorithm. Eur Spine J 22(12):2787-2799. https ://doi.org/10.1007/s00586-013-2850-1

30. Zimmerli W (2010) Clinical practice. Vertebral osteomyelitis. N Engl J Med 362(11):1022-1029. https://doi.org/10.1056/NEJMc p0910753

31. Grados F, Lescure FX, Senneville E, Flipo RM, Schmit JL, Fardellone P (2007) Suggestions for managing pyogenic (non-tuberculous) discitis in adults. Joint, Bone, Spine Revue du rhumatisme 74(2):133-139. https://doi.org/10.1016/j.jbspin.2006.11.002

32. Matsumoto T, Mine T, Hayashi T, Kamono M, Taoda A, Higaki M, Hasebe T (2017) CT Fluoroscopy-guided transsacral intervertebral drainage for pyogenic spondylodiscitis at the lumbosacral junction. Cardiovasc Intervent Radiol 40(1):125-129. https://doi. org/10.1007/s00270-016-1452-9

33. Yang S-C, Fu T-S, Chen H-S, Kao Y-H, Yu S-W, Tu Y-K (2014) Minimally invasive endoscopic treatment for lumbar infectious spondylitis: a retrospective study in a tertiary referral center. BMC Musculoskeletal Disorders 15:105. https://doi. org/10.1186/1471-2474-15-105

Publisher's Note Springer Nature remains neutral with regard to jurisdictional claims in published maps and institutional affiliations. 